the representative of the responsible authority.'

NIMMAGADDA, S. \& JONES, C. N. (2008) Consultant psychiatrists' knowledge of their role as representatives of the responsible authority at mental health review tribunals. Psychiatric Bulletin, 32 $366-369$.

Charles Montgomery Consultant Psychiatrist, SpecialistTeam in Early Psychosis (STEP) Wonford House Hospital, Dryden Road, Exeter EX2 5AF, email: cmontgomery@nhs.net

doi: $10.1192 / p b .33 .1 .38 b$

\section{Relationships in secure psychiatric units}

Relationships between residents in secure psychiatric units cause clinicians a great deal of concern (Dein \& Williams, 2008).

The effective management of such liaisons pre- and post-discharge also needs to be considered.

Relationships in secure settings can and will happen. Robust plans need to be made while individuals are in-patients and in anticipation of their wish to move on together. Strict boundaries need to be maintained, although joint participation in various therapeutic activities can be facilitative and could be a positive rehabilitative endeavour. With the evolution of gender specificity in secure care, separation of units or wards may reduce the instances of relationships. Clinical decision-making needs to be at the fore, especially when relationships end, as all mental disorders are at risk of relapse, thereby increasing risks.

Those in relationships are unlikely to leave a unit (sometimes after being together for years) at the same time, for example where one individual is much further down the treatment and rehabilitation pathway, and they may not reside at the same post-discharge location.
Decisions on harmonising care pathways can be difficult, requiring a comprehensive assessment of risk and management. The involvement of the Ministry of Justice in restricted cases can make decisionmaking more complex. Guidance from the Ministry of Justice at an early stage would be particularly advantageous, possibly inviting case-workers to care programme approach meetings.

Finally, we would like to note that relationships may not only be partnerships, but also include friendships.

DEIN, K. \& WILLIAMS, P. S. (2008) Relationships between residents in secure psychiatric units: are safety and sensitivity really incompatible? Psychiatric Bulletin, 32, 284-287.

Muthusamy Natarajan Specialty Registrar (ST5) in Forensic Psychiatry, The Hatherton Centre, Stafford ST16 3AG, email: muthusamy.natarajan@sssft.nhs. uk, Jayanth Srinivas Consultant Forensic Psychiatrist, The Hatherton Centre, Stafford doi: 10.1192/pb.33.1.39

\section{Mobile telephone text messaging of clinic appointments in psychiatry}

Psychiatric out-patient clinics can have a high non-attendance rate. Department of Health figures for England showed 19.1\% of appointments in mental health clinics were missed compared with an overall figure of $11.7 \%$ for all specialties (Department of Health, 2003). Many strategies have emerged to try to improve attendance and, more recently, trials of short-message-service appointment reminders have been reported in other specialties (Downer et al, 2006; Geraghty et al, 2008; Koshy et al, 2008). These have reduced non-attendance rates and have been inexpensive to run. There do not appear to be any studies involving textmessage appointment reminders in mental health services and we decided to carry out a feasibility study in our general adult psychiatry out-patient clinics.

Unfortunately, we identified some unexpected difficulties. In our random sample of 50 patients, 38 (76\%) owned a mobile telephone, which is in keeping with the national average. Of these 38 people, however, only $74 \%$ could remember their telephone number and only $53 \%$ were agreeable to being contacted by text message.

Short-message-service appointment reminders do, on the surface, appear to be a potentially useful and cost-effective method of improving psychiatric outpatient clinic attendance rates. Our study, however, highlights some difficulties in maximising the effectiveness of such a service and it seems unlikely that psychiatric clinics would provide as impressive results as those reported in other settings.

DEPARTMENT OF HEALTH (2003) Hospital Activity Statistics. Department of Health.

DOWNER, S. R., MEARA, J. G., DA COSTA, A. C. \& SETHURAMAN, K. (2006) SMS text messaging improves outpatient attendance. Australian Health Review, 30, 389-386.

GERAGHTY, M., GLYNN, F., AMIN, M., \& KINSELLA, J. (2008) Patient mobile telephone 'text' reminder: a novel way to reduce non-attendance at the ENT out-patient clinic. Journal of Laryngology and Otology, 122, 296-298.

KOSHY, E., CAR, J. \& MAJEED, A. (2008) Effectiveness of mobile-phone short message service (SMS) reminders for ophthalmology outpatient appointments: observational study. BMC Ophthalmology, 8, 9-14.

*Andrew Donaldson Specialist Registrar, Perth City Community Mental HealthTeam, 8 St Leonard's Bank, Perth PH1 5HH, Australia, email: andrew. donaldson@nhs.net, Ziad Tayar Specialty Trainee, Perth City Community Mental HealthTeam, Perth, Australia

doi: 10.1192/pb.33.1.39a

\title{
corrections
}

Services for ethnic minorities: a question of trust. Psychiatric Bulletin 32, 401-402.

p. 401, col. 2, para. 1: The second sentence should read: High rates of illness and sectioning, it is simplistically assumed in the media and elsewhere, are the product of inappropriate practice on the part of mental health professionals although no one has ever shown that the Mental Health Act is used inappropriately in individual cases.

p. 402, col. 2, para. 2: The second sentence should read: This will bring a new responsibility on all of us to broadcast a more positive message to ethnic minority patients, their families and communities. That message is simple: you will be treated fairly.

The online version of this article has been corrected post-publication in deviation from print and in accordance with this correction.

Seamus MacSuibhne and Aoife $\mathrm{Ni}$ Chorcorain ('I wish to speak to a psychiatrist please': psychiatric vocabulary in phrase books. Psychiatric Bulletin, 32 359).

Only 4 of the 12 questions were answered correctly by more than half the participants and for 4 questions the proportion of those answering correctly did not differ significantly from the 0.25 that would be expected from chance (Consultant psychiatrists' knowledge of their role as representatives of the responsible authority at mental health review tribunals. Psychiatric Bulletin, 32, 366-369).

doi: 10.1192/pb.33.1.39b 